\title{
Marcas e vestígios de narrativas televisuais na abertura da telenovela $O$ Astro
}

\author{
Paula Regina Puhl* \\ Roberto Tietzmann**
}

\section{Resumo}

O artigo tem como temática o estudo das sequências de abertura de produções audiovisuais veiculadas na televisão que possuem mais de uma versão. As aberturas introduzem a identidade visual do programa, funcionam como um contrato firmado com os espectadores ao dar crédito a elenco e equipe e interpretam visualmente temas da narrativa. Como objeto foram escolhidas as aberturas da telenovela da TV Globo O Astro nas versões de 1977 e 2011. O objetivo é comparar as duas aberturas por meio de uma análise exploratória a partir dos elementos visuais e da forma como esses se relacionam com a temática principal da narrativa. Foi verificada a importância desse recurso televisual tanto para a apresentação da narrativa de ambas aberturas quanto a sua representatividade estética que é marcada pelo contexto histórico e tecnológico de produção e veiculação.

Palavras chave: O Astro. TV Globo. Telenovela. Abertura. Remake.

\section{Marks and traces of televisual narratives in the opening titles of the soap opera $O$ Astro \\ Abstract}

The article studies opening sequences of audiovisual productions broadcast on television that have more than one version. These sequences operate as a con-

* Professora dos cursos de Jornalismo, Publicidade e Propaganda, Relações Públicas e do curso de Produção em Cinema Audiovisual na PUC-RS, Porto Alegre-RS, Brasil. Doutora em Comunicação Social. Pesquisadora da FAPERGS e diretora Regional/Sul da Intercom. E-mail: paula.puhl@pucrs.br

** Professor do Programa de Pós-Graduação em Comunicação Social e dos cursos de Publicidade e Propaganda e de Cinema e Audiovisual na PUC-RS, Porto Alegre-RS, Brasil. Doutor em Comunicação Social pela PUC-RS.

E-mail:rtietz@pucrs.br 
tract with the audience, establishing credit for the cast and crew, and as a visual interpretation of the narrative themes, besides introducing the program's visual identity. As objects were chosen the opening sequences of both versions of TV Globo's soap opera O Astro in 1977 and its remake in 2011. The article aims to compare the two sequences through an exploratory analysis of the visual elements and how these relate to the main themes of the narrative. The study verified the importance of this feature for both the televisual presentation of the narrative in both sequences as its aesthetic representation marked by technological and historical context of production and broadcast.

Keywords: O Astro. TV Globo. Soap opera. Opening titles. Remake.

\section{Las marcas y las huellas de las narraciones televisivas en la apertura de la telenovela $O$ Astro \\ Resumen}

El artículo tematiza el estudio de las secuencias de apertura de las producciones audiovisuales transmitidas en la televisión que tienen más de una versión. Las secuencias operan como un contrato con el público, dando el crédito para el elenco y el equipo, y como una interpretación visual de los temas narrativos, además de presentar la identidad visual del programa. Como objetos fueron elegidos aberturas de la TV Globo de la telenovela O Astro en las versiones de 1977 y 2011. El artículo objetiva comparar las dos aberturas a través de un análisis exploratorio de los elementos visuales y cómo éstos se relacionan con el tema principal de la narrativa. Se verificó la importancia de este recurso, tanto para la presentación televisiva de la narrativa en las secuencias como en su representación estética que está marcado por el contexto tecnológico e histórico de producción y veiculación.

Palabras clave: O Astro. TV Globo. Telenovela. Abertura. Remake.

\section{Introdução}

\section{A s telenovelas pertencem ao cotidiano de muitos brasileiros $\triangle$ desde a inauguração da televisão no país, na década de 50, $\angle$ L suas características e influência na identidade nacional são tema de inúmeras pesquisas acadêmicas a partir de autores como Maria Immacolata Vassallo de Lopes, Esther Hamburger, Anna Maria Balogh, entre outros. Neste artigo, propomos como recorte do campo as sequências de abertura de telenovelas, seg- mentos nos quais são apresentados o título e os créditos de elenco}


e equipe acompanhados de uma interpretação visual da temática do programa. Selecionamos as telenovelas que possuem mais de uma versão, elegendo como objeto $O$ Astro, veiculada pela Rede Globo pela primeira vez em 1977-1978, com uma remake em 2011, sendo então denominada pela emissora como "novela das $23 \mathrm{~h}$ ". O objetivo do artigo é fazer uma comparação entre as aberturas da versão de 1977 e a de 2011, a fim de apontar as semelhanças e as diferenças nas suas apresentações por meio de uma análise técnica e temática e também discutir a pertinência estética desse recurso televisual que é o primeiro contato do telespectador com a narrativa pretendida pelos autores.

Dados quantitativos sustentam a afirmação de que a televisão faz parte da vida dos brasileiros. Segundo a pesquisa feita pelo Grupo de mídia de SP Mídia Dados Brasil (2011, p.50) "o país tem uma população de 192.278,4 mil habitantes e 57.037,3 mil domicílios ocupados". A pesquisa foi realizada com um universo de $40.434 \mathrm{mil}$ pessoas e constatou-se que $97 \%$ dos entrevistados tinham assistido pelo menos uma vez na semana a programação televisiva. Outra informação importante é que 95,1 \% dos domicílios ocupados possuem um aparelho de televisão. Entre as emissoras de televisão aberta, a Rede Globo destaca-se por seu alcance e abrangência e também pelo share (número de televisores ligados) com 51,20\%.

Ao considerar não somente a importância da televisão e sua penetração nos lares brasileiros, mas também a participação da telenovela na concepção da grade de programação, segundo o Guia Ilustrado da Rede Globo (2010, p.5) "a emissora produz aproximadamente 2,5 mil horas anuais de novelas e programas - recorde mundial de teledramaturgia que equivale a duração de 100 longasmetragens por mês - e mais de 1,8 mil horas anuais de telejornalismo". Estes dados complementam diversas pesquisas acerca das telenovelas no Brasil, como a de Hamburger (1998), que relata que as telenovelas são termômetros da vida cotidiana e dos costumes da sociedade mostrando a vida privada para o grande público.

Além disto, Lopes (2003) destaca que a televisão, principalmente por meio das telenovelas, expressa e alimenta as angústias e ambivalências que caracterizam as mudanças sociais e econô- 
micas, tendo também uma direta relação com o desenvolvimento da nação e de seu povo, fazendo assim parte de uma comunidade nacional imaginada.

Baseado nesses breves comentários sobre a importância da telenovela para o Brasil, nosso intuito é complementar essas pesquisas situando o foco nas sequências de abertura desse produto televisivo, que funcionam tanto como um contrato firmado com os espectadores (ao indicar nomes de elenco e equipe), quanto como uma interpretação visual de temas da narrativa e como uma referência de identidade visual única do programa. $\mathrm{O}$ conceito de Comunicação Gráfica aplicada à televisão foi formulado em emissoras norte-americanas a partir da década de 1950 conforme Krasner (2008) sendo baseado na ideia de que cada programa tem uma marca específica, podendo ser reproduzido tanto em meios eletrônicos quanto impressos sustentando uma identidade visual coerente. No caso da Globo, a formalização da Comunicação Visual foi primeiro organizada por Cyro del Nero conforme Alencar (2002) e, posteriormente, consolidada por Hans Donner e seus sucessores de acordo com Machado (2005). As sequências de abertura das duas edições da telenovela $O$ Astro mantém o conceito de identidade visual dos programas usados na TV Globo desde seus primeiros anos.

A abertura introduz uma lista de nomes de elenco e equipe, vinhetas de entrada e saída de blocos e créditos finais, na maioria das vezes trazendo uma interpretação visual dos temas do programa sem usar cenas dele diretamente. Em outras palavras, é uma realização separada da produção dos demais segmentos e episódios e que acompanham o programa durante toda a sua veiculação.

Segundo o Guia Ilustrado TV Globo (2010), as aberturas das telenovelas da emissora possuem em média 50 segundos e são utilizadas tanto para anunciar quanto para assinar os programas. Elas começaram a ter o padrão que é reconhecido atualmente com o designer Hans Donner, atuante na emissora desde 1975. Como característica das aberturas produzidas a partir dessa data são citados os recursos de computação gráfica, referências a obras de artistas plásticos, maquetes, inspirações cinematográficas, animações, entre outras fontes e técnicas. No entanto, independente 
da mudança nos recursos, as aberturas sempre buscaram manter um diálogo com a trama principal.

\section{O Astro e as características das telenovelas}

De acordo com Lopes (2003, p.17) a telenovela no Brasil é reconhecida como "agente central do debate sobre a cultura brasileira e a identidade do país”. A penetração desse produto na sociedade brasileira, para a autora se deve a capacidade das telenovelas em representar, abordar um "repertório comum” que permite com que as pessoas de diferentes lugares, classes e sexo se reconheçam umas às outras.

A telenovela a partir de suas características, seja no conteúdo, seja no formato, pressupõe e potencializa uma relação de alteridade e, ao mesmo tempo, de pertencimento junto ao público que consegue se reconhecer como uma única nação. Essa proximidade entre público e televisão faz considerar que os conteúdos que são apropriados pelas telenovelas acabam por chamar a atenção desses telespectadores e se tornam pauta para conversas e observações cotidianas.

As tramas das novelas são, em geral, pautadas em oposições entre homens e mulheres, gerações, classes sociais, urbano e rural, arcaico e moderno. Além disso, como destaca Lopes (2003), a telenovela sintetiza público e privado, político e doméstico, notícia e ficção, masculino e feminino.

O enredo da telenovela $O$ Astro não é diferente das características listadas por Lopes (2003) em suas duas versões, de acordo com o Guia Ilustrado TV Globo (2010) trata da ascensão econômica e social do ilusionista Herculano Quintanilha (interpretado na primeira versão por Francisco Cuoco e, na segunda, por Rodrigo Lombardi). Herculano consegue a confiança de Márcio, filho do empresário Salomão Hayala, que é obrigado a assumir os negócios depois do assassinato do pai. Esse fato foi responsável pelo sucesso da trama, pois todos queriam saber: "quem matou Salomão Hayala?".

Escrita por Janete Clair, a primeira versão foi exibida de seis de dezembro de 1977 a oito de julho de 1978 em 186 capítulos no 
horário das 22h. Já o remake foi reescrito por Alcides Nogueira e Geraldo Carneiro, com colaboração de Tarcísio Lara Puiati e Vitor de Oliveira e teve inicio em 12 de julho de 2011 com 60 capítulos exibidos às $23 \mathrm{~h}$. Segundo relato dos autores (O PÚBLICO..., 2012), foi feita uma releitura da história de Janete Clair trazendo alterações como a mudança do assassino de Salomão. As personagens não são completamente boas ou más, de acordo com as ações que protagonizam elas reagem de formas diferentes causando incertezas ao telespectador, o que busca deixar a história mais dinâmica e menos previsível em relação aos folhetins clássicos.

\section{Problematizando adaptações, refilmagens e remakes}

Uma prática corrente na indústria do audiovisual em suas diversas instâncias é a ideia de transportar narrativas, personagens e temáticas de um meio a outro, bem como tomar obras audiovisuais previamente realizadas como fonte para novas produções. Tais processos são identificados por uma variedade de termos como adaptação, homenagem, atualização, transposição, versão, refilmagem, remake entre outros tendo como ponto em comum a necessidade de sinalizar ao mesmo tempo a continuidade com o que foi previamente realizado e um caráter de novidade e atualidade.

Tais práticas se iniciaram com o desenvolvimento da indústria cinematográfica em meados do século 20, destaca Musser (1994) e se adequaram a um modelo de produção sistematizado de grande orçamento por serem entendidos como um investimento de menos risco conforme coloca Verevis (2006, p.3):

Para os produtores de cinema, remakes são constantemente pensados como sendo capazes de proporcionar modelos adequados, e uma espécie de garantia financeira, para o desenvolvimento de projetos baseados em um estúdio. Em um contexto comercial, remakes são "pré-vendidos" para o seu público, porque os espectadores supostamente teriam alguma experiência prévia, ou, pelo menos, possuiriam uma "imagem narrativa" da história original - um filme anterior, literatura ou de outra propriedade [intelectual] - antes de entrar em sua releitura específica.

Exemplos no cinema são abundantes. Zanger (2006) cita que há mais de 50 versões cinematográficas de Carmen realizadas desde 
o período do cinema mudo. Forrest e Koos (2002) destacam que mesmo filmes tidos como determinantes de um gênero como o noir O Falcão Maltês (The Maltese Falcon, 1941) é na verdade a terceira versão a ser feita do texto de Dashiel Hammett tendo as duas anteriores despertado menos atenção de público e crítica e ocupando menos espaço no relato histórico da área.

A televisão torna este panorama ainda mais complexo por aumentar a demanda por conteúdo e a quantidade de espaços e canais onde são veiculados tais programas. Moran (2009) aponta o sucesso global da série colombiana Yo Soy Betty, La Fea, veiculada e traduzida no Brasil como Betty, a Feia, como um exemplo deste panorama onde os programas podem tanto ser vendidos em seu registro original quanto comercializados como um conjunto de personagens, roteiros e parâmetros que podem então ser desdobrados e adaptados às circunstâncias regionais de cada cultura. De maneira semelhante, novelas da TV Globo também são vendidas para exibição dublada ou apenas como formato e roteiros destinadas a mercados internacionais.

A primeira telenovela veiculada na Rede Globo é de 1965, chamada Ilusões Perdidas, desde lá foram apresentadas para o público diversos remakes. De acordo com levantamento feito pelos autores, tendo como fonte de pesquisa o Guia Ilustrado da TV Globo (2010), destacamos os seguintes remakes, considerando somente a produção dos anos 90 até 2010: Mulheres de Areia (1993), Irmãos Coragem (1995), Anjo Mau (1997), Pecado Capital (1998), O Profeta (2006), Sinhá Moça (2006), Ciranda de Pedra (2008), O Astro (2011) e Gabriela (2012). Esse cenário mostra que a emissora tem como prática apostar em releituras em diversos horários de veiculação das telenovelas.

\section{Telenovela, aberturas e traduções gráficas}

Machado (2005) diz que as telenovelas brasileiras possuem uma construção teleológica, ou seja, possuem uma narrativa seriada caracterizada por uma única narrativa ou narrativas entrelaçadas que se sucedem ao longo de todos os capítulos, os quais, no início, um 
ou mais conflitos colaboram para um desequilíbrio estrutural, para que, posteriormente, a narrativa consiga restabelecer até o último capítulo a resolução desses conflitos entre as personagens. Nessa dinâmica, a telenovela, por ser uma obra aberta e sujeita a acréscimos narrativos tanto de ambientes como de personagens, será a audiência que também irá influenciar no andamento da criação da narrativa.

Balogh (2002) também comenta essa característica serial da telenovela e também sinaliza para a necessidade de mecanismos de reiteração da narrativa, pois é por intermédio dessa "recapitulação" que é possível "reassegurar o entendimento do espectador já cativo, mas que eventualmente tenha perdido algum capítulo, e para fisgar o espectador não cativo, seduzindo-o para o acompanhamento de uma trama maior com a qual não está familiarizado" (BALOGH, 2002, p.166).

Este esforço para trazer o espectador casual e dispersivo em direção à atenção e ao envolvimento com a narrativa passa pela elaboração de uma identidade visual na abertura da novela, responsável por apresentar temáticas que serão constantes ao longo do folhetim. Uma abertura, enfim, não existe sozinha, isolada do programa que a inspira e movida apenas por um propósito decorativo.

A regularidade da presença de aberturas nas telenovelas da TV Globo estabelece uma continuidade com a tradição de produção de sequencias semelhantes no cinema. Para o designer Saul Bass (apud Crook, 1986), responsável pela ruptura estética modernista dos créditos cinematográficos na década de 1950, as aberturas deveriam ajudar a enunciar a intenção e a temática da obra que introduzem sob pena de serem taxadas como representantes de uma retórica visual vazia, sem consequências no andamento do filme. Tal sombra da irrelevância desagradava Bass:

Era algo perturbador quando, tendo estabelecido o valor de algum tratamento especial para os títulos do filme, eu via um número deles sendo feitos como um tipo de sapateado irrelevante. Mesmo coerência estilística, parecia, não era suficiente. Mais importante, precisava haver uma atitude compartilhada entre o crédito e o filme (BASS apud CROOK, 1986, p.12).

Esta atitude compartilhada que Bass defende pode ser entendida como um espelhamento temático entre o filme e a sequência. 
Este espelhamento reinterpreta visualmente a obra maior dentro da menor, escolhendo o que mostrar e o que esconder para preservar o interesse do espectador. As considerações de Tomachewski, ainda que baseadas na literatura, se aplicam a obras audiovisuais de viés narrativo:

No decorrer do processo artístico, as frases particulares combinam-se entre si segundo seu sentido e realizam uma certa construção na qual se unem através de uma idéia ou tema comum. As significações dos elementos particulares da obra constituem uma unidade que é o tema (aquilo de que se fala) (TOMACHEWSKI, 1976, p.169).

Os motivos são pequenas partículas da obra, um resumo absoluto de alguma característica ou trecho da história. Tomachewski (1976) cita exemplos de motivos como sendo "A noite caiu", "o herói morreu" e "uma carta chegou". No caso das aberturas, elas podem incorporar diferentes tipos de motivos, interpretando-os graficamente, tipograficamente e imageticamente. A preocupação de Saul Bass com a atitude compartilhada entre filme e crédito se constitui, portanto, a partir da qualidade do próprio filme em motivar seus espectadores a assisti-lo com prazer, algo que está imerso na subjetividade de cada um. Depende da sensibilidade do comunicador gráfico encontrar uma solução que respeite a intenção da obra e a ela conduza além de oferecer um equilíbrio entre o conhecido e o inesperado.

\section{As aberturas de $O$ Astro: reprises temáticas e diferenças tecnológicas}

As sequências de abertura das duas edições da telenovela $\mathrm{O}$ Astro, veiculadas em 1977-1978 e em 2011 trazem outro detalhe para a complexidade da tradução visual: como é uma releitura, tem um compromisso de dialogar com velhos e novos espectadores, traduzindo os temas da narrativa e sinalizando o que trazem de novo a ela. A distância de mais de 30 anos entre as duas aberturas as posiciona em dois momentos distintos tanto de estilos gráficos de cada período quanto de recursos tecnológicos para a elaboração 
de suas imagens. Ainda assim, há elementos que se repetem entre ambas, uma alusão também à regularidade dos elementos centrais da trama, centrada no personagem do ilusionista e vidente Herculano Quintanilha (Francisco Cuoco na primeira versão, Rodrigo Lombardi na segunda).

Em seguida, fazemos uma comparação dos elementos constantes e renovados presentes em cada abertura, partindo dos pressupostos para interpretação de créditos em Tietzmann (2005) e desdobrando-os em uma descrição das aberturas e em uma análise de suas temáticas e intertextos.

\section{Descrição da abertura de O Astro 1977//978}

A abertura original traz 26 planos em cerca de 1 min20s de duração, acompanhada pela música Bijuterias, de João Bosco e Aldir Blanc. Os segmentos apresentam dois grandes temas: exploram a projeção sobre rostos de símbolos relacionados a um repertório místico, ocultista ou histórico; além deste, também estabelecem Herculano Quintanilha como o protagonista da trama pela repetição de sua imagem em destaque. Ao longo dos planos também são sobrepostas os letreiros com nomes de elenco e equipe no tipo de letra padrão da TV Globo. Não serão analisadas a forma e o conteúdo das legendas pois não interpretam visualmente as temáticas da narrativa.

Figura 1 - Quadros selecionados da abertura de O Astro, versão 1977/1978.

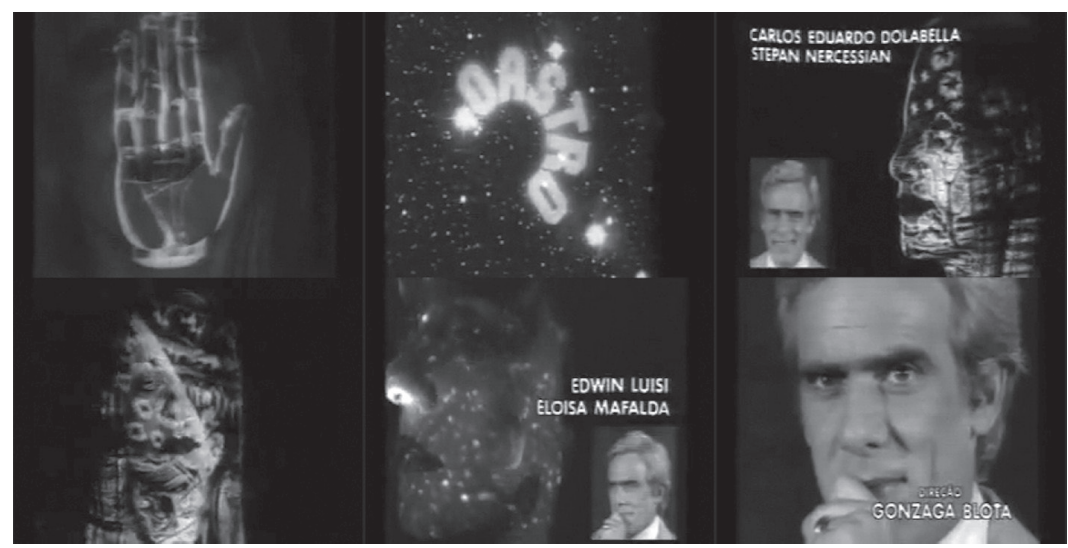

Fonte: http://www.youtube.com/watch?v=CezCzOjDkr4 Acesso em: 04/08/2012. 
A abertura começa com uma aproximação em um rosto de um homem em meio a um fundo neutro, trazendo uma expressão insegura na face, sobre cuja pele é projetada a imagem de uma galáxia. $\mathrm{O}$ segundo plano traz um rosto de uma mulher sobre cuja face é projetada a gravura da palma de uma mão sem inscrições. A mulher tem a expressão serena movendo discretamente o rosto para baixo. Uma fusão conduz a uma imagem de estrelas em cuja frente um círculo amarelo gira e cresce na tela a se aproximar do espectador. Quando o movimento cessa se revela o nome da telenovela, escrito em meia-lua em um tipo de letra desenhado inteiramente por linhas retas ou ângulos de $45^{\circ}$ ou $90^{\circ}$ e sem adornos.

$\mathrm{O}$ quarto plano traz um detalhe do rosto do mesmo homem da primeira imagem com um anjo projetado sobre sua face. Uma fusão de imagem conduz ao próximo plano, no qual o mesmo anjo é projetado sobre os rostos do homem e da mulher que se afastam sem cruzar os olhares. Um corte brusco revela um close no ator Francisco Cuoco (no papel de Herculano Quintanilha, mas sem a caracterização do personagem em seus shows nos quais porta maquiagem e um turbante) sobre um fundo vermelho que olha para a esquerda do quadro sorrindo e gira o rosto para o lado direito, sugerindo que observara a cena anterior e então dedica sua atenção ao próximo plano.

Vemos o rosto de uma jovem loura, novamente sobre um fundo neutro, que tem sobre sua face a projeção em negativo de uma gravura em alto contraste onde um homem tenta alcançar o horizonte sob a abóbada de um céu estrelado. Esta imagem funde-se com o próximo plano no qual a mesma mulher é vista quase de perfil e é aplicada uma imagem do protagonista no canto inferior esquerdo com um sorriso onde transparece uma expressão de cinismo.

Um corte nos leva a um close de um aperto de mãos que tem projetado sobre a pele a ilustração de um olho direito com traços orientais destacados por uma linha de maquiagem azul e a pele vermelha. No próximo plano, um rosto de mulher tem uma galáxia projetada sobre a pele e gira à esquerda, multiplicado por um filtro de prisma sobre a lente da câmera; no canto inferior direito o protagonista observa os detalhes. 
Nos próximos dois planos, mãos inicialmente em posição de concha se abrem e revelam cartas de tarô colocadas sobre um pano azul em círculo com duas cartas ao centro. Os dois planos seguintes retomam a projeção da gravura da mão sobre o rosto da mulher loura, desta vez à direita do quadro em close em contraponto ao pequeno close de Quintanilha no canto superior esquerdo da imagem portando um olhar preocupado. O plano seguinte retoma o rosto do protagonista sobre o fundo vermelho, desta vez olhando para a esquerda e expressando um sorriso de satisfação. Um corte retoma o rosto da mulher loura, revelado pela projeção de uma gravura de estilo antigo identificada com o signo de peixes.

Um breve plano do protagonista olhando diretamente para a câmera com expressão atenta e questionadora é seguido por uma imagem do rosto de mulher, agora revelado por uma gravura antiga do signo de sagitário. Retorna um plano breve do rosto do personagem-título, agora com um sorriso de satisfação. Volta o rosto da mulher com a gravura do signo de gêmeos projetada em movimento sobre seu rosto, seguida por um plano congelado de Quintanilha atento e sério.

Um rosto de homem com expressão neutra e olhos praticamente cerrados tem a carta do enforcado do tarô projetado sobre seu rosto. Ele diminui na tela até o centro com um afastamento rápido, sendo então acompanhado no plano por mais um retrato congelado de Quintanilha no canto inferior direito e as legendas na metade esquerda inferior.

No próximo plano, dois rostos com a estampa do calendário asteca projetado sobre os mesmos se erguem. Em seguida o olho visto anteriormente projetado sobre o aperto de mãos reaparece sobre o rosto da mulher loura, mostrado em movimento.

O penúltimo plano traz uma projeção dupla do olho, posicionada de maneira que é possível entendê-la como um olhar direto ao espectador. No que seria um corte em $180^{\circ}$, o rosto do personagem-título toma a tela e seu olhar lentamente esboça um sorriso, encerrando a abertura. 


\section{Análise temática da abertura de O Astro 1977/1978}

Uma análise temática da abertura aponta detalhes sobre as origens das soluções apresentadas e sugere vínculos entre as imagens apresentadas e as narrativas trazidas no segmento inicial apresentado ao longo de toda a temporada.

Um elemento recorrente na abertura é a presença de rostos que recebem a projeção de uma imagem estática. É uma solução que convoca o espectador a construir sua compreensão da imagem tanto na relação sequencial trazida pela edição quanto na justaposição interna à imagem, sobre a qual a textura projetada nada tem de naturalizado em sua apresentação. As raízes para tal apresentação visual têm um antecessor imediato no cinema e por extensão nas experiências artísticas de vanguardas do século 20.

A projeção de imagens sobre corpos trazem influências dos créditos de abertura de Moscou contra 007 (From Russia With Love, 1963) e 007 contra Goldfinger (Goldfinger, 1964), respectivamente o segundo e o terceiro filmes da série do espião James Bond. Criadas pelo designer Robert Brownjohn, a primeira explora a projeção de imagens e legendas estáticas sobre o corpo de uma dançarina conhecida por se apresentar com cobras, cita King (2005, p.67) e a última apresenta a projeção de imagens-chave dos filmes anteriores sobre uma vedete cujo corpo é pintado de dourado.

Conforme King (2005), o designer Brownjohn identifica sua principal referência com as obras fotográficas e cinematográficas de László Moholy-Nagy em suas experiências com projeções, sobreposições e múltiplas exposições durante as décadas de 1920 a 1940. A ideia de choque e estranhamento presente em vários movimentos modernistas e trazida à tela por Nagy é assim relida com um propósito de identidade visual e suporte à narrativa tanto nos filmes de James Bond quanto na telenovela brasileira.

Chama a atenção no conteúdo das imagens sobrepostas aos rostos a ampla variedade de elementos apresentados como indicadores de misticismo e esoterismo: signos do zodíaco, fotos de constelações e galáxias, tarô e até um disco de calendário asteca. A mistura livre entre astronomia, astrologia e culturas 
pré-colombianas colocada ao lado de Quintanilha se insere em uma tendência em voga durante a década de 1970 - a de misturar fatos científicos com extrapolações, identificada com publicações de grande sucesso desde finais da década de 1960. Livros como Eram os Deuses Astronautas? (Von Däniken, 1973) e Homens e Civilizações Fantásticas (Hutin, 1972), entre outros, difundiam fantasia travestida de ciência aos seus leitores, uma forma do folhetim sugerir a atualidade do ilusionista para sua plateia de massa.

A repetição do rosto do ator Francisco Cuoco sem que sobre ele seja sobreposta nenhuma imagem afirma seu papel como protagonista da narrativa. Ele já era um rosto conhecido do público, já tendo trabalhado com a novelista Janete Clair em quatro telenovelas anteriores, sendo protagonista em três delas, cita Xexéo (2005). A intercalação de seu rosto entre as faces do casal e sua inserção como um segmento da imagem sugerem um papel ambíguo entre quem observa as ações e quem as influencia, uma postura alinhada com as ações do personagem Herculano Quintanilha.

Uma vez que toda telenovela possui uma história de amor, ao longo da abertura é possível interpretar também a aproximação dos rostos do homem e da mulher até seu encontro em uma única face com os dois olhos lado a lado no penúltimo plano da narrativa. Ainda que esta leitura esteja encoberta pelas imagens esotéricas projetadas sobre os rostos, é fiel às convenções do meio.

\section{Descrição da versão de 0 Astro 201 I}

A abertura do remake de $O$ Astro atualiza os recursos tecnológicos para criar suas imagens, mantendo em comum pontos da temática e elementos de sugestão esotérica. De forma decisiva, aqui estão presentes recursos de edição, animação e composição de imagens em pós-produção, o que faz com que esta versão não tenha cortes de imagem aparentes criando passagens entre os elementos presentes em cena. 
Figura 2 - Quadros selecionados da abertura de O Astro, versão 2011.

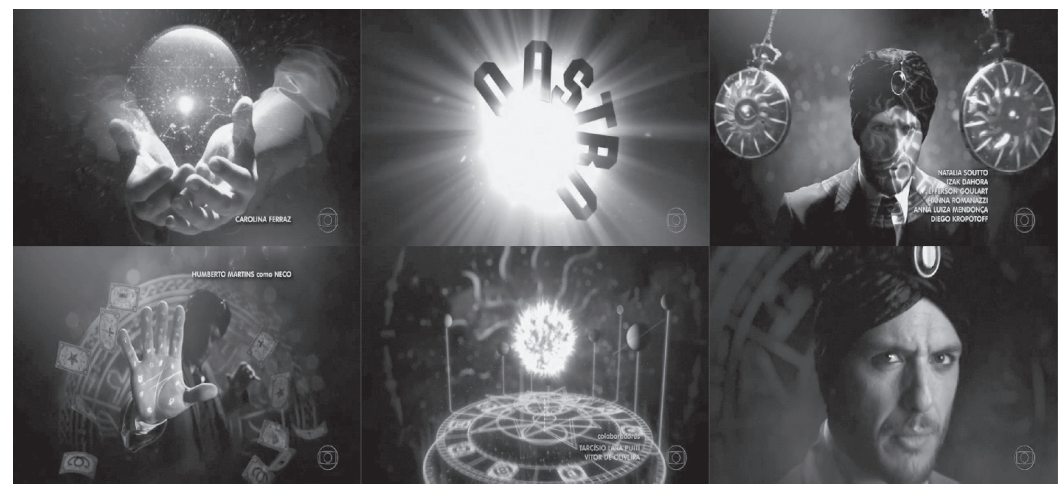

Fonte: http://www.youtube.com/watch?v=toyL1oTss8A. Acesso em: 04/08/2012

A primeira imagem traz as mãos de Herculano Quintanilha aninhadas como se carregassem algo que ainda não vemos. Elas surgem da escuridão, revelando ainda que o personagem veste camisa branca e terno azul. As mãos se abrem e se forma uma esfera transparente animada com as constelações do zodíaco que ilumina o seu entorno com um brilho lilás e algumas estrelas. As mãos desaparecem suavemente e uma imagem de uma galáxia toma o fundo da tela, enquanto as constelações são convertidas visualmente nos símbolos do zodíaco facilmente identificáveis como touro e virgem na forma de agrupamentos de pontos luminosos que se desfazem após um instante.

Um facho de luz toma o centro da tela, intenso e dourado, ocultando a galáxia que tomava o fundo até então. Do centro da luz, surge o título $O$ Astro em arco com um tipo de letra e diagramação semelhantes à primeira versão. Para facilitar a leitura, as letras são escuras e se destacam em contraste com a iluminação que emana do centro.

A luz do plano anterior se intensifica e toma toda a tela, dissolvendo-se em um fundo de tom entre o lilás e o rosa sobre o qual dezenas de pedras lapidadas avançam em direção ao olhar do espectador. Após alguns segundos, se aproxima do centro do quadro um globo feito de quatro anéis de metal e um disco com 
diversas inscrições decorativas relacionadas ao zodíaco e à astrologia. Este globo é circundado por um disco no qual mais uma vez estão representados os símbolos gráficos dos signos acompanhados de filetes decorativos.

A visão do espectador passa pelo interior do globo, próximo aos anéis, revelando seus detalhes e se aproxima do rosto do protagonista Herculano Quintanilha (Rodrigo Lombardi) que surge desfocado das sombras e levanta o rosto revelando a maquiagem de palco do personagem e expressão séria. Herculano está caracterizado como aparece nos espetáculos que realiza ao longo da trama - os mesmos terno azul e camisa branca do primeiro segmento da abertura, somado aqui a um turbante de tecido escuro com uma pedra preciosa posicionada na altura da testa.

À frente e por detrás do rosto de Herculano oscilam pêndulos decorados com uma referência visual ao sol. Continuando neste segmento as casas do zodíaco são sobreimpressas com luz no rosto de Herculano, com o sol posicionado sobre seu olho direito. A passagem dos dois últimos pêndulos oculta o rosto do personagem e o revelam à frente de mais um disco do zodíaco, desta vez apresentado da cintura para cima e envolvido em gelo seco.

Com um gesto, o personagem-título na penumbra estende a mão até um foco de luz mais próximo do espectador. Com traços dourados se desenham os símbolos do zodíaco em sua mão bem como linhas identificadas com a quiromancia. Por detrás do personagem, voam cartas com símbolos gráficos como estrelas, punhais e taças com um líquido escuro.

O movimento de Herculano congela e sua imagem se desfoca, saindo pela parte inferior da tela. Na parte superior as cartas continuam a voar enquanto se desenha com fios luminosos um modelo reduzido do sistema solar. As imagens são emolduradas por grafismos de fogo e estrela e terminam por se afastar do espectador e reunirem no interior de uma esfera que dissolve-se no olho maquiado de Quintanilha. A imagem se afasta e vemos o rosto do personagem outra vez. A joia do turbante reluz e a tela se escurece. 


\section{Análise temática da abertura de 0 Astro $201 \mathrm{I}$}

A abertura da segunda versão da telenovela constroi suas imagens a partir do repertório definido na primeira versão atendendo às mesmas necessidades: estabelecer Herculano Quintanilha como protagonista e agregar sugestões visuais de misticismo ao conjunto da narrativa.

A definição de Quintanilha como protagonista na versão mais recente é feita de uma maneira ainda mais clara que na primeira versão. Aqui ele é o único humano que aparece em cena que tenha sido registrado por uma câmera sendo acompanhado de diversos elementos animados digitalmente. O sublinhar do protagonismo é feito pelas reações que seus movimentos provocam: já no primeiro plano o abrir de suas mãos revela um universo (no qual, alegoricamente, se desenrolará a trama) e com o cintilar da joia do turbante a abertura e o universo se encerram dando continuidade ao episódio.

O que é novo aqui é a ideia de espetáculo presente na caracterização de Herculano com o figurino de palco, no gesto que aproxima a palma da mão ao espectador e também nos pêndulos que oscilam à volta dele, uma sugestão visual de hipnose conforme difundida popularmente no cinema segundo Barrett (2010). Se na primeira versão Quintanilha parecia influenciar a aproximação do casal nesta versão suas ações dialogam com o espectador ao se desenrolarem no que seria o eixo geométrico da profundidade. Durante boa parte da abertura "avançamos" tela adentro, penetrando no universo que partiu das mãos do ilusionista. A imagem "recua" apenas nos momentos finais onde o retorno à face do protagonista serve como um fechamento.

Também característica da nova versão há algo que é uma marca da aplicação das novas tecnologias de edição e pós-produção audiovisual: há um imperativo do movimento. Se algo está na tela, tem de se mover, um sintoma da própria ausência de materialidade do que é representado. Ironicamente, o único elemento concreto da nova abertura é o ator Rodrigo Lombardi que é econômico em seus movimentos. 


\section{Considerações finais: aproximações e distanciamentos entre as aberturas de 1977 e 2011}

A nova versão da abertura relê temáticas visuais estabelecidas pela primeira como a projeção de imagens sobre rostos humanos, o movimento de abertura de mãos, um detalhe do olho maquiado e a profusão de representações dos signos do zodíaco. Desta vez, estão ausentes as referências explícitas a culturas pré-colombianas e à mera apropriação visual direta de gravuras. Isto oferece ao espectador do remake um mundo totalmente animado onde mesmo os elementos que parecem antigos como o globo formado pelos discos cuja aparência evoca metal trabalhado em um passado indefinido, mas é a representação de um imaginário astrológico contemporâneo.

Mesmo com essas diferenças, ambas aberturas utilizaram a mesma trilha sonora para marcar o conceito de remake e possuir identificação com o público, mas a diferença mais clara está no destaque dado ao protagonista que está em mais evidência na abertura de 2011.

A importância da abertura de uma telenovela vai além do seu caráter informativo de marcação para o início da narrativa, ela funciona como um mosaico representativo de imagens que fazem sentido ao telespectador que acompanha a trama até o final.

A força dramática pode ser potencializada pela técnica utilizada em cooperação com a temática proposta pelo enredo, entretanto as significações proporcionadas por essa união possuem sentidos diferentes a partir do contexto em que são tanto produzidas, quanto veiculadas, a compreensão está ligada a familiarização com os códigos imagísticos por parte do público, ou seja, independente dos recursos videográficos usados na aberturas, um fator indispensável é a cultura imagística do telespectador.

Dessa forma, esse artigo fez uma reflexão sobre como é possível, a partir de uma análise de aberturas de telenovelas, mais especificamente remakes, estabelecer contrastes entre épocas e também atentar para a importância de estudos desse recurso que tem a finalidade de mostrar/esconder o que a trama pretende, sem deixar em segundo plano a responsabilidade em estabelecer 
o primeiro elo entre o público e a narrativa. As aberturas são os únicos companheiros fixos dos telespectadores que vão ter que acompanhar cada capítulo para possivelmente conseguirem desvelar as significações que a abertura mostrou desde a primeira vez que foi veiculada. Nesse sentido, consideramos a abertura como um componente, uma marca da narrativa televisual enquanto está sendo veiculada, e por outro lado, quando a trama adormece ainda poderemos encontrar os vestígios do tempo da sua produção.

\section{Referências}

ALENCAR, Mauro. A Hollywood brasileira: panorama da telenovela no Brasil. São Paulo: Editora Senac, 2002.

BALOGH, Anna Maria. O discurso ficcional na TV. São Paulo: Editora da Universidade de São Paulo, 2002.

BARRETT, Deirdre. Hypnosis and Hypnotherapy. Santa Barbara: ABC-CLIO, 2010.

CROOK, Geoffrey. Television graphics: From Caption Card to Computer. Oxford: Built By Robots Press, 1986.

FORREST, Jennifer; KOOS, Leonard (Orgs.). Dead Ringers: the remake in theory and practice. Suny Series, Cultural Studies in Cinema/Video. Albany : State University of New York Press, 2002.

GRUPO DE MÍDIA SÃO PAULO. Mídia Dados Brasil 2011, São Paulo, 30 de julho de 2011. Disponível em: http://midiadados.digitalpages.com.br/home. aspx?edicao=3. Acesso em: 10 jul. 2012.

HAMBURGER, Esther. Diluindo Fronteiras: A televisão e as novelas no cotidiano. In: SCHWARCZ, Lilian Moritz (Org.). História da vida privada no Brasil: contrastes da intimidade contemporânea. v. 4. São Paulo: Companhia das Letras, 1997. p.439-487

HUTIN, Serge. Homens e civilizações fantásticas. São Paulo: Hemus Livraria Editora, 1972.

KING, Emily. Robert Brownjohn: sex and typography,1925-1970, life and work. Londres: Laurence King Publishing, 2005.

KRASNER, Jon S. Motion graphic design: applied history and aesthetics. Nova Iorque: Focal Press, 2008.

LOPES, M. I. V. Telenovela brasileira: uma narrativa sobre a nação. Revista Comunicação \& Educação, São Paulo, ECA-USP, v. 1, n. 26, p. 17-34, 2003. 
MACHADO, Arlindo. A televisão levada a sério. 4.ed São Paulo: Senac, 2005. MORAN, Albert. New flows in global TV. Bristol: Intellect Books, 2009.

MUSSER, Charles. The emergence of cinema: the american screen to 1907. Los Angeles: California University Press, 1994.

O PÚBLICO mostrou-se cúmplice, revelam Alcides Nogueira e Geraldo Carneiro. Globo.com. Rio de Janeiro, 22 maio 2012. Disponível em: http://tvg. globo.com/novelas/o\%20astro/Bastidores/noticia/2011/10/o-publico-mostrou-se-cumplice-revelam-alcides-nogueira-e-geraldo-carneiro.html. Acesso em: 12 abr. 2013.

PUHL, Paula R. Televisão e literatura: a transcodificação do conteúdo no caso Agosto. São Paulo: Adaltech, 2006.

TIETZMANN, Roberto. O filme antes do filme: A retórica gráfica dos créditos de abertura cinematográficos. 2005. 310 f. Dissertação (Mestrado em Comunicação Social) - Faculdade de Comunicação Social, Pontifícia Universidade Católica do Rio Grande do Sul.

TOMACHEVSKI, Boris. Temática. In: TOLEDO, Dionísio de O.(Org). Teoria da literatura: formalistas russos. 2.ed. Porto Alegre: Globo, 1976. p. 169-204.

TV GLOBO NOVELAS E MINISSÉRIES/ PROJETO MEMÓRIA GLOBO (Guia Ilustrado). Rio de Janeiro: Jorge Zahar, 2010.

VEREVIS, Constantine. Film remakes. Edinburgh: Edinburgh University Press, 2006.

VON DÄNIKEN, Erich. Eram os deuses astronautas? São Paulo: Melhoramentos [Círculo do Livro], 1973.

XEXÉO, Arthur. Janete Clair: a usineira de sonhos - Perfis do Rio. Rio de Janeiro: Relume Dumará, 2005.

ZANGER, Anat. Film remakes as ritual and disguise: from carmen to ripley film culture in transition series. Amsterdam: Amsterdam University Press, 2006.

Recebido: 28/09/2012 Aceito: 20/03/2013 